\title{
Editorial
}

\section{Unthemed Issue}

This issue of Anthropology of the Middle East is unthemed, but there is a definite continuity to its articles. Previously, we have had themed issues - for example, on kinship, migration, medical anthropology, Central Asia - and the articles here touch on the same topics, so they relate very well to earlier issues.

The first two articles in a way complement each other: the first, by Muyassar Turaeva, is about women who travel to gain a livelihood for the whole family, and the second, by Mary Elaine Hegland, is about men who migrate. There are points of similarity and difference within the two contexts, and we hope that further research on similar themes will take into consideration all of these points raised after close scrutiny of difficult circumstances.

The articles on rituals are about two different topics: the first, by Aidarbek Kochkunov, is about hospitality, and the second, by El-Sayed el-Aswad, is about religious rituals. The first is performed within a family setting, the second during a public event. The context of the first subject is the kinship structure, while that of the second is male or female spaces, which are gatherings within the kernel of kin structure. Thus, both of these rituals relate to kinship. Kochkunov's article details traditional aspects of the hospitality ritual that were unchanged for over a thousand years and how this custom has recently undergone transformations. Despite the effects of globalisation and influences from other cultures, Kochkunov concludes that the basic identity and cultural specificity of this custom have been maintained. El-Aswad's article emphasises the relationship between the appearance and the hidden (the link between the clergy and the hidden imam), between bodily expressions and cosmology, and between religious beliefs and present needs. It also analyses the construction of symbolic locations (the cubic building, qadamal-Mahdi). Religious rituals that take place in a public setting provide a larger society for individuals, who become participants at the event, presenting themselves and voicing their inner problems within a set cosmology.

The article on nafs of the Alawite in south-eastern Turkey by Laila Prager shows socialisation processes at a philosophical and embryonic level. This is a very refreshing and essential article for understanding core values that constitute 
local societies and the way that these values relate to the notion of the cosmos as a whole. Although generally divorce is considered in a negative light, khul; a new procedural law in Egypt, gives women the right to unilateral divorce. Analysed in the article by Nadia Sonneveld, these adjustments to the divorce law can be seen as reflecting positive and fundamental changes that are taking place in Egyptian society today.

Given the situation of the Middle East today and what the media headlines are saying, should it be surprising that the topics of our articles relate to issues such as private social life, birth, religious rituals and divorce? Is this because the authors do not choose to cover matters of political or media importance, or are they restricted in their efforts to do so? Is it because people's everyday realities of life are more embedded in ritual and kinship? Or is there a flight into kinship due to the harsh realities of the Middle East? Perhaps there is some truth in all of these questions, and there is more to be considered as well. We could easily move in the direction of kinship and politics and the importance of nepotism for keeping the political situations of various countries of the region as they are. We could also include discussions about law as it relates to individualism and kinship, as well as the very important topic of rituals in politics and the use of symbols that are meaningful to every region within media politics.

In the Middle East we still have a vivid memory of 'ancient times', something that has not been transformed gradually, as in Western Europe, or erased, as in the Americas and Africa, not to speak of Australia. So while there is great pressure and suffering in the Middle East, kinship relations and their associated rituals are still the means by which human lives remain interconnected and by which the dignity and identity of the region are sustained. Documenting them in these pages will protect them as the heritage of a future that is under great daily peril. 